\title{
Preparation of Carbon Nanowall and Carbon Nanotube for Anode Material of Lithium-Ion Battery
}

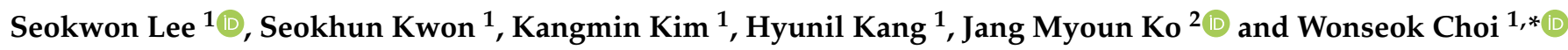 \\ 1 Department of Electrical Engineering, Hanbat National University, Daejeon 34158, Korea; \\ dltjrdnjs000@naver.com (S.L.); kwon1567@naver.com (S.K.); talk9797@naver.com (K.K.); \\ hikang@hanbat.ac.kr (H.K.) \\ 2 Department of Chemical and Biological Engineering, Hanbat National University, Daejeon 34158, Korea; \\ jmko@hanbat.ac.kr \\ * Correspondence: wschoi@hanbat.ac.kr
}

check for updates

Citation: Lee, S.; Kwon, S.; Kim, K.; Kang, H.; Ko, J.M.; Choi, W.

Preparation of Carbon Nanowall and Carbon Nanotube for Anode Material of Lithium-Ion Battery. Molecules 2021, 26, 6950. https://doi.org/10.3390/ molecules 26226950

Academic Editors: Wan Soo Yun, Sung-Hoon Kim and Kyriakos Porfyrakis

Received: 23 September 2021 Accepted: 17 November 2021 Published: 17 November 2021

Publisher's Note: MDPI stays neutral with regard to jurisdictional claims in published maps and institutional affiliations.

Copyright: (c) 2021 by the authors. Licensee MDPI, Basel, Switzerland. This article is an open access article distributed under the terms and conditions of the Creative Commons Attribution (CC BY) license (https:/ / creativecommons.org/licenses/by/ $4.0 /)$.

\begin{abstract}
Carbon nanowall (CNW) and carbon nanotube (CNT) were prepared as anode materials of lithium-ion batteries. To fabricate a lithium-ion battery, copper $(\mathrm{Cu})$ foil was cleaned using an ultrasonic cleaner in a solvent such as trichloroethylene (TCE) and used as a substrate. CNW and CNT were synthesized on $\mathrm{Cu}$ foil using plasma-enhanced chemical vapor deposition (PECVD) and water dispersion, respectively. CNW and CNT were used as anode materials for the lithium-ion battery, while lithium hexafluorophosphate $\left(\mathrm{LiPF}_{6}\right)$ was used as an electrolyte to fabricate another lithium-ion battery. For the structural analysis of CNW and CNT, field emission scanning electron microscope (FE-SEM) and Raman spectroscopy analysis were performed. The Raman analysis showed that the carbon nanotube in composite material can compensate for the defects of the carbon nanowall. Cyclic voltammetry (CV) was employed for the electrochemical properties of lithium-ion batteries, fabricated by CNW and CNT, respectively. The specific capacity of CNW and CNT were calculated as $62.4 \mathrm{mAh} / \mathrm{g}$ and $49.54 \mathrm{mAh} / \mathrm{g}$. The composite material with CNW and CNT having a specific capacity measured at $64.94 \mathrm{mAh} / \mathrm{g}$, delivered the optimal performance.
\end{abstract}

Keywords: carbon nanowall; carbon nanotube; PECVD; lithium-ion battery; cyclic voltammetry; FE-SEM

\section{Introduction}

Lithium-ion batteries (LIB) are widely used in energy storage devices, such as portable electronic devices, which are essential in daily life. So far, graphite has been used the most as the anode material for LIB, because it has good stability during charging and discharging. When charging LIB, pulverization may occur due to a change in volume during the insertion of lithium-ions into the anode material [1]. Graphite has high stability because small volume changes occur during the charging process.

Recently, research on carbon materials and graphene as anode materials for lithiumion batteries has been conducted [2-4]. There are several types of carbon allotropes [5,6], including graphene, graphite, diamond, carbon nanowalls (CNW), carbon nanotubes $(\mathrm{CNT})$, and fullerenes. Graphene has a flat 2D structure in which carbon atoms form $\mathrm{sp}^{2}$ bonds in a hexagonal shape, while graphite is a structure in which graphene forms multiple layers by $\pi-\pi$ bonds $[7,8]$. In $\mathrm{CNW}$, graphene grows vertically to form a nanowall structure and carbon nanotubes are bonded by rolling graphene into a cylindrical shape. Diamond is structurally rigid because the bonds among carbon atoms are $\mathrm{sp}^{3}$ bonds [9].

In this paper, the characteristics of LIB, using CNW and CNT as anode materials, were investigated. CNW and CNT offer advantages of high electrical conductivity and the fast diffusion of electrons and lithium ions due to their wide surface area. The composite material of the CNW and CNT were also applied to the LIB as anode material and the characteristics were investigated. 


\section{Experimental Design}

The copper $(\mathrm{Cu})$ foil for the current collector needs to be cleaned because of impurities and the oxidation layer. To remove the impurities, the $\mathrm{Cu}$ foil was ultrasonically cleaned using TCE, acetone, methanol, and distilled water for $10 \mathrm{~min}$. Figure $1 \mathrm{a}$ shows the schematic diagram of the $\mathrm{Cu}$ foil cleaning process. The oxidation layer of $\mathrm{Cu}$ foil, caused by exposure to atmosphere, was removed by diluted sulfuric acid.

(a)

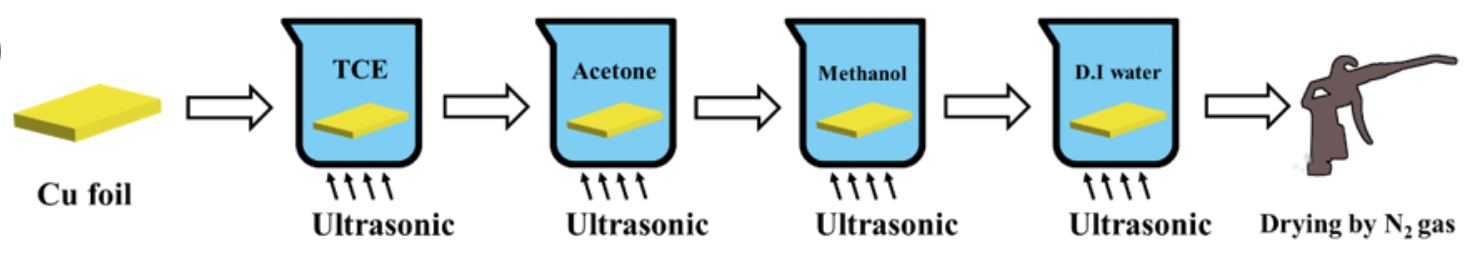

(b)

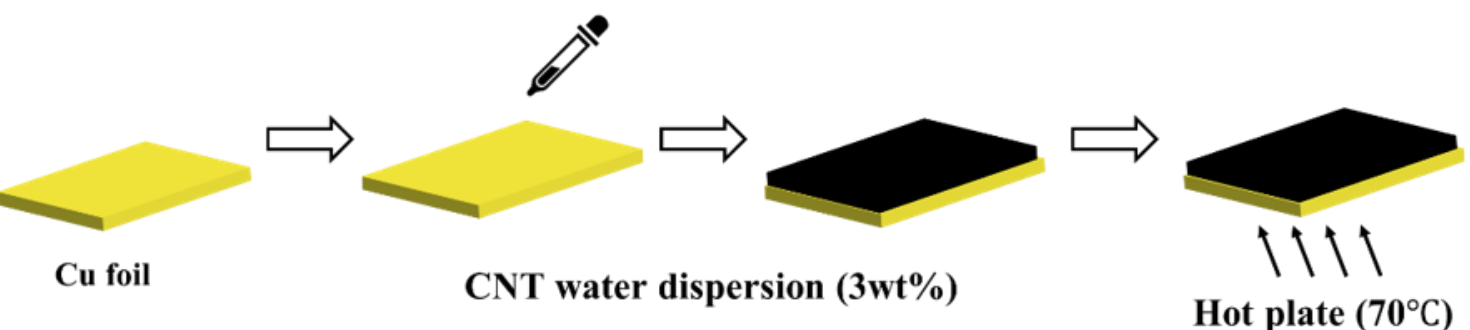

(c)

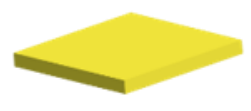

Cu foil

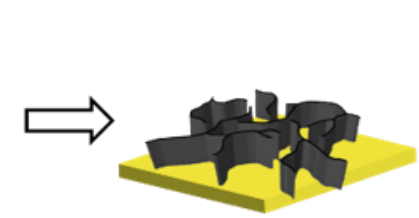

CNW

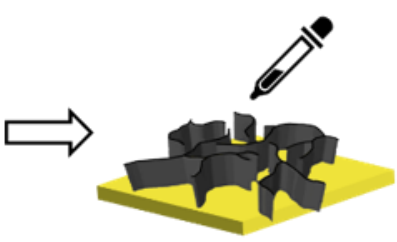

CNT water dispersion (3wt \%)

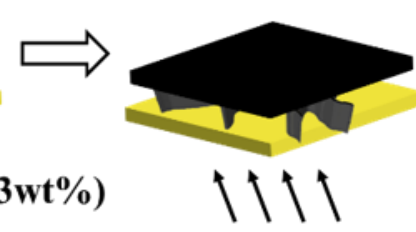

Hot plate $\left(70^{\circ} \mathrm{C}\right)$

Figure 1. (a) The schematic diagram of the $\mathrm{Cu}$ foil cleaning process, (b) synthesizing the CNT using water dispersion method and (c) synthesizing the composite material with CNW and CNT.

The $\mathrm{CNW}$ was grown on $\mathrm{Cu}$ foil using plasma-enhanced chemical vapor deposition (PECVD, Woosing CryoVac, ASTEX type, $2.45 \mathrm{GHz}$ microwave, Uiwang, Korea). The cleaned $\mathrm{Cu}$ foil was inserted in the PECVD chamber and the vacuum level of the chamber to the base pressure value $5 \times 10^{-5}$ Torr was decreased using a vacuum pump. The mixture of $\mathrm{H}_{2}$ gas and $\mathrm{CH}_{4}$ gas was injected at a ratio of 2:1 into the chamber with the $\mathrm{Cu}$ foil heated to $700{ }^{\circ} \mathrm{C}$. The injected gases were ionized by plasma power of $1300 \mathrm{~W}$ and the carbon atoms were deposited on $\mathrm{Cu}$ foil to synthesize CNW. Figure 2 shows the schematic diagram of the PECVD with the process of growing CNW. In addition, Table 1 shows the conditions for growing the CNW via PECVD.

Table 1. The conditions of growing CNW via PECVD.

\begin{tabular}{cccccc}
\hline Substrate & Base Pressure & Working Pressure & Chamber Atmosphere & Temperature & Growth Time \\
\hline $\mathrm{Cu}$ foil & $5 \times 10^{-5}$ Torr & $4 \times 10^{-2}$ Torr & $\mathrm{H}_{2}: \mathrm{CH}_{4}=2: 1$ & $700^{\circ} \mathrm{C}$ & $15 \mathrm{~min}$ \\
\hline
\end{tabular}

Using the MWCNTs water dispersion ( $3 \mathrm{wt} \%,>95+\%$, OD: 5-15 nm, Length $50 \mu \mathrm{m}$ ), purchased from US Research Nanomaterials, the CNT was synthesized on Cu foil. A MWCNT water dispersion solution of $3 \mathrm{~mL}$ was dropped onto the $\mathrm{Cu}$ foil by pipette and dried by hotplate at $70{ }^{\circ} \mathrm{C}$ for $20 \mathrm{~min}$. Figure $1 \mathrm{~b}$ shows the schematic diagram of synthesizing CNT using the water dispersion method. 


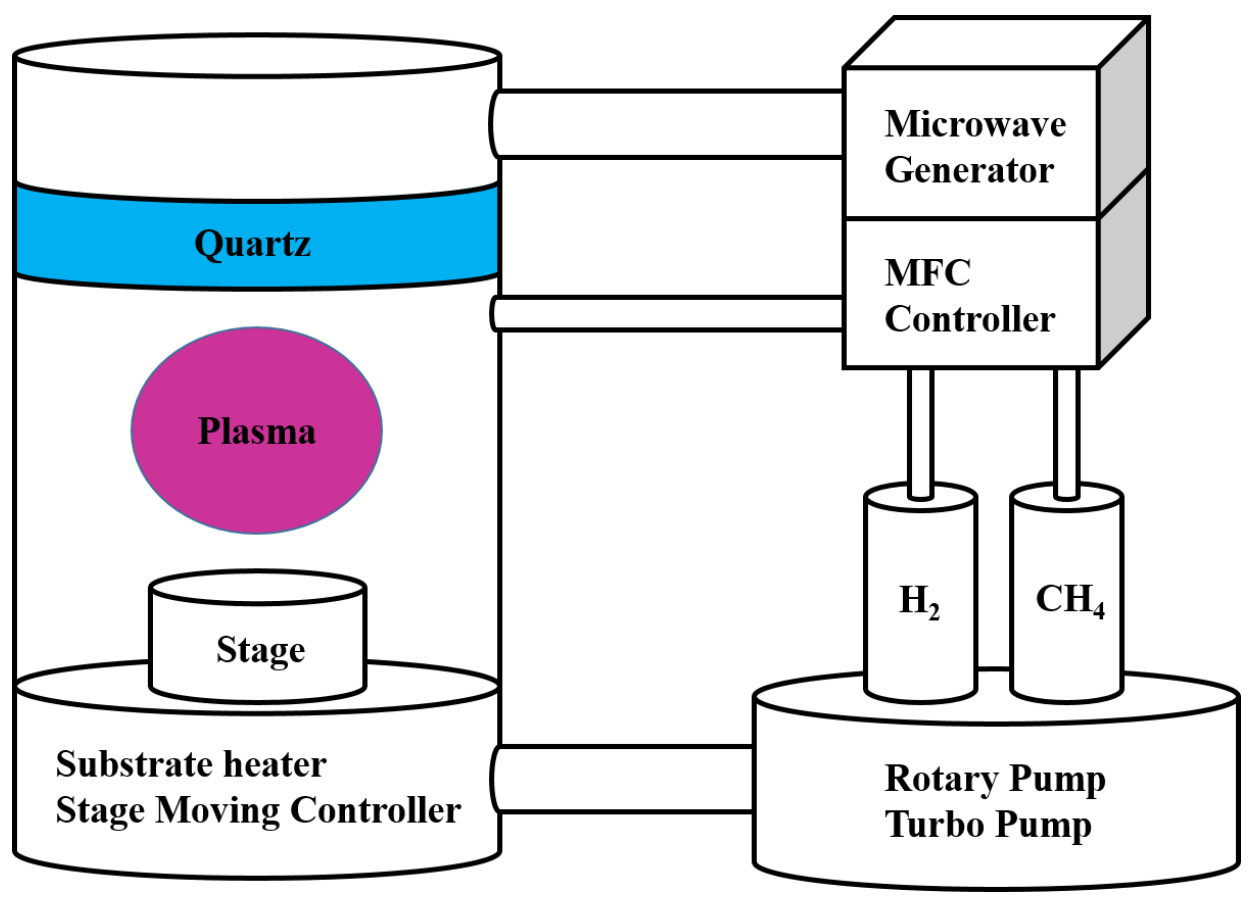

Figure 2. The schematic diagram of PECVD.

The composite material of CNW and CNT was prepared in two steps. The CNW was grown on $\mathrm{Cu}$ foil by PECVD, and the CNT was synthesized on CNW using the water dispersion method. Figure $1 \mathrm{c}$ shows the schematic diagram fot synthesizing the composite material with CNW and CNT.

To investigate the surface and cross-section structure, the Raman shift (micro-Raman Spectrometer, FEX, Seongnam, Korea) and field emission scanning electron microscopy (FE-SEM, Hitachi S-4800) image were analyzed for each sample. In the Raman analysis, the excitation laser wavelength was $\sim 531 \mathrm{~nm}$, the excitation laser power was $\sim 0.3 \mathrm{~mW}$ and the spectral resolution was $\sim 1.9$ to $2.1 / \mathrm{cm}$. To examine the electrochemical properties of anode materials prepared by CNW and CNT, the coin cell (CR2032, Wlcos, Gunpo, Korea) was manufactured. The lithium metal ( $150 \mu \mathrm{m}$ thickness) was used as a counter electrode, while the CNW and CNT were used as working electrodes. All the coin cells used $1 \mathrm{M}$ $\mathrm{LiPF}_{6}($ Panax Etec) in EC/DMC $=4 / 6(v / v)$ as an electrolyte, while polyethylene (Celgard, $20 \mu \mathrm{m})$ was used as the separator. Cyclic voltammetry (CV, WizECM-1200, Daejeon, Korea) was performed to measure the specific capacity of the anode materials prepared by $\mathrm{CNW}$ and CNT.

\section{Results and Discussion}

Figure 3 shows the FE-SEM surface and cross-section images of each sample. Figure $3 a$ is the FE-SEM surface image of the CNW, and it can be confirmed that the wall structure of the CNW was well grown by PECVD. The cylindrical structure of CNT was also well synthesized on $\mathrm{Cu}$ foil using the water dispersion method. This can be confirmed in the FE-SEM surface image in Figure 3b. Figure 3c-e show the FE-SEM cross-section image of $\mathrm{CNW}, \mathrm{CNT}$, and composite material, respectively. It can be confirmed that CNT was well synthesized on the CNW as composite material.

Raman analysis was performed to investigate the structure of CNW, CNT and composite material with CNW and CNT. In Figure 4a, the Raman shift for each sample shows the $\mathrm{D}$ peak, G peak, $\mathrm{D}^{\prime}$ peak and 2D peak. A D peak indicates when a defect in the sample was observed at $1349 \mathrm{~cm}^{-1}$. The $\mathrm{G}$ peak, which is often observed in graphene, such as those found in carbon materials, was observed at $1582 \mathrm{~cm}^{-1}$, while 2D peak was observed at $2697 \mathrm{~cm}^{-1}$ as a peak affected by the $\pi-\pi$ bond in the graphene [10]. In contrast to CNTs, it can be seen that the D peak of CNWs were measured with a particularly strong intensity, 
which can be attributed to the edge of graphene with vertically grown wall-shaped structures in CNW [11,12]. A strong D peak was observed in the Raman shift of CNW, but a D peak with similar intensity to that of CNT was observed in the composite material. It seems that the wall-shaped structure of the $\mathrm{CNW}$, which was the cause of the D peak, was reduced due to the bonding with the $\mathrm{CNT}$ in the composite material. The $\mathrm{I}_{\mathrm{D}} / \mathrm{I}_{\mathrm{G}}$ and $\mathrm{I}_{2 \mathrm{D}} / \mathrm{I}_{\mathrm{G}}$ ratio of $\mathrm{CNW}, \mathrm{CNT}$, and the composite material, calculated based on the results of Raman shift intensity, are shown in Figure $4 \mathrm{~b}$. The $\mathrm{I}_{\mathrm{D}} / \mathrm{I}_{\mathrm{G}}$ ratio, which indicates the defects of the sample, also shows a high value due to the wall-shaped structure of the CNW, while the $\mathrm{I}_{2 \mathrm{D}} / \mathrm{I}_{\mathrm{G}}$ ratio represents the thickness of graphene [13]. The lower the $\mathrm{I}_{2 \mathrm{D}} / \mathrm{I}_{\mathrm{G}}$ ratio is, the thicker graphite is grown by PECVD. By the $\mathrm{I}_{2 \mathrm{D}} / \mathrm{I}_{\mathrm{G}}$ ratio of each sample in Figure $4 \mathrm{~b}$, all of the CNW and CNT consisted of multi-layered graphene.

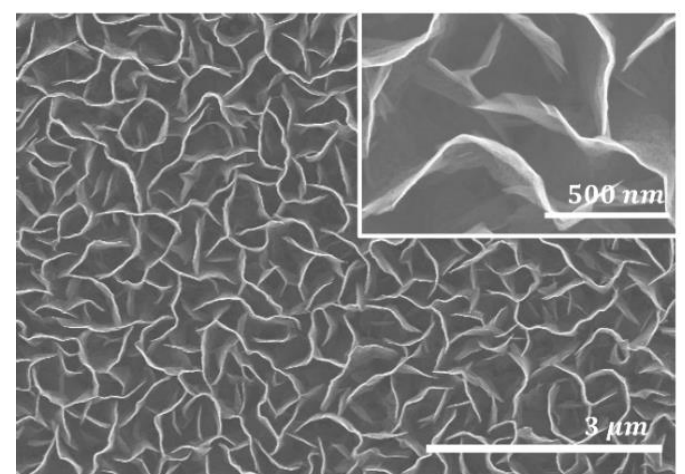

(a)

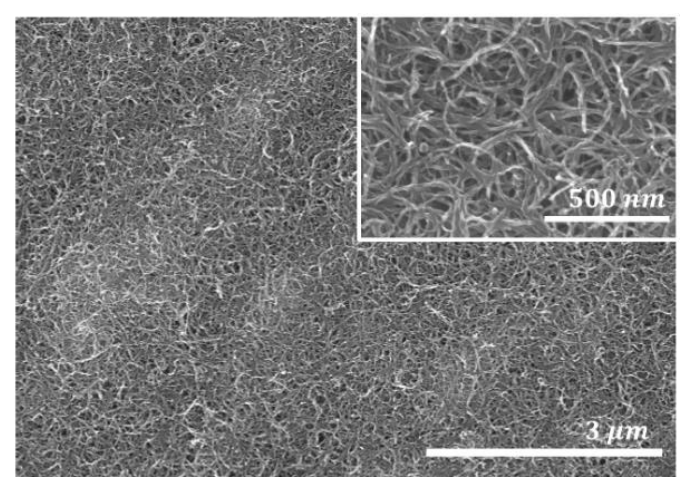

(b)

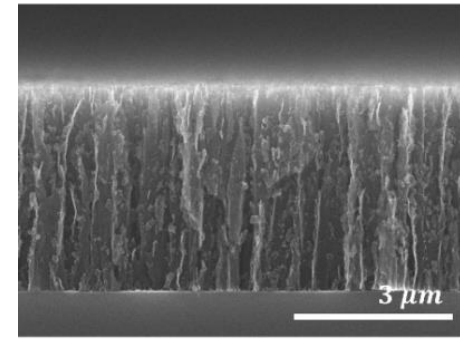

(c)

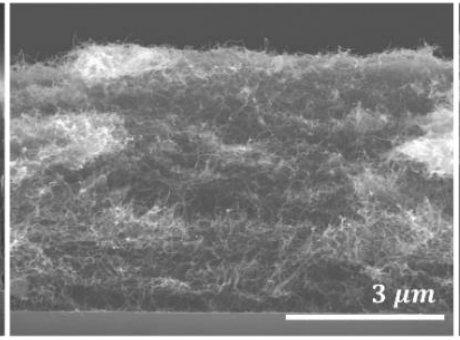

(d)

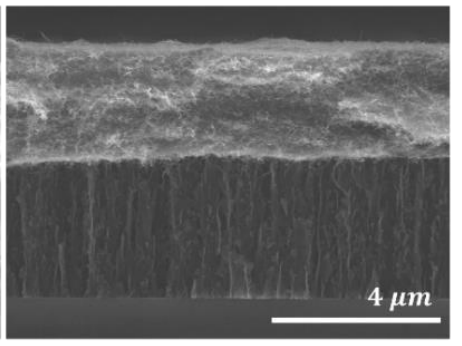

(e)

Figure 3. The FE-SEM surface image of the (a) CNW (scale bar, $3 \mu \mathrm{m}$ ) with enlarged CNW (inset, scale bar, $500 \mathrm{~nm}$ ) and (b) CNT (scale bar, $3 \mu \mathrm{m}$ ) with enlarged CNT (inset, scale bar, $500 \mathrm{~nm}$ ). The FE-SEM cross-section image of the (c) CNW (scale bar, $3 \mu \mathrm{m}$ ), (d) CNT (scale bar, $3 \mu \mathrm{m}$ ) and (e) composite material with CNW and CNT (scale bar, $4 \mu \mathrm{m}$ ).

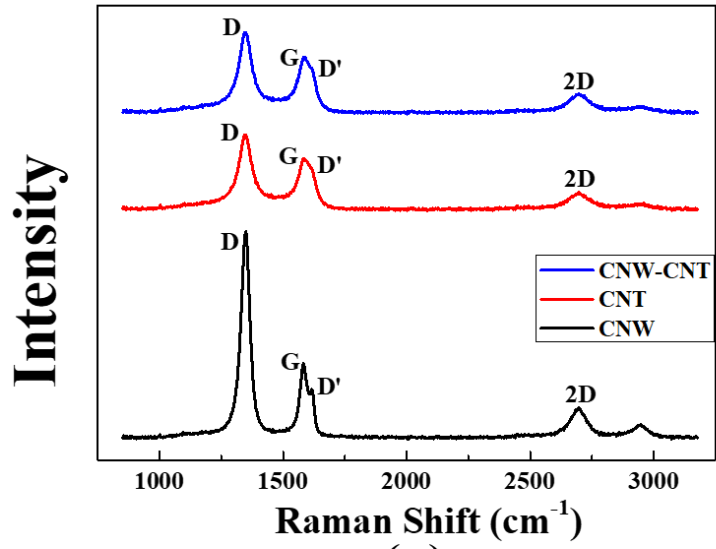

(a)

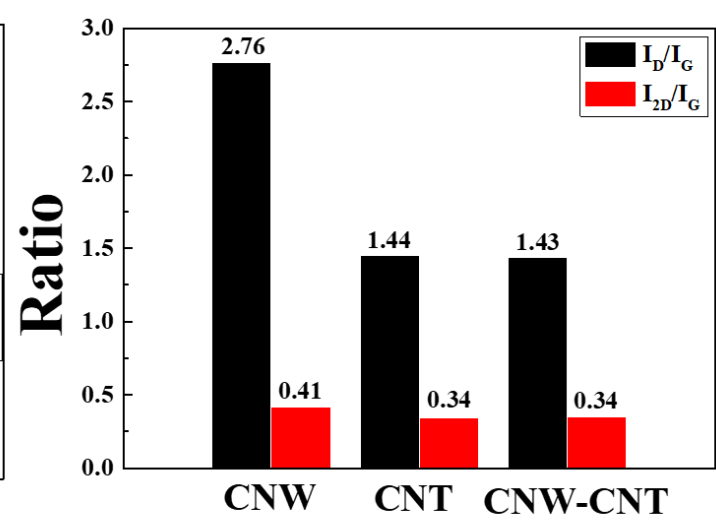

(b)

Figure 4. (a) The Rama shift of the CNW (black line), CNT (red line), and composite material with CNW and CNT (blue line). (b) The $\mathrm{I}_{\mathrm{D}} / \mathrm{I}_{\mathrm{G}}$ and $\mathrm{I}_{2 \mathrm{D}} / \mathrm{I}_{\mathrm{G}}$ ratio of $\mathrm{CNW}, \mathrm{CNT}$ and composite material from Raman shift. 
Cyclic voltammetry $(\mathrm{CV})$ was performed with a typical coin cell and working electrode made from CNW, CNT, and composite material, respectively. The CV was measured in a $0 \sim 1.7 \mathrm{~V}$ potential window and the scan rate was $0.1 \mathrm{mV} / \mathrm{s}$ for 12 th cycle. Figure 5 shows the $\mathrm{CV}$ graph of $\mathrm{CNW}, \mathrm{CNT}$, and composite material for each cycle. In the $\mathrm{CV}$ graph, the oxidation peak indicates the charging process of the LIB since lithiation occurs in anode materials. The CV graph of CNW is shown in Figure 5a, representing one oxidation peak at $0.11 \mathrm{~V}$. In Figure $5 \mathrm{~b}$, the CV graph of the CNT shows the three oxidation peaks at $0.25 \mathrm{~V}$, $0.42 \mathrm{~V}$, and $0.54 \mathrm{~V}$. Figure $5 \mathrm{c}$ shows the $\mathrm{CV}$ graph of the composite material with CNW and $\mathrm{CNT}$, and there are two oxidation peaks at $0.18 \mathrm{~V}$ and $0.53 \mathrm{~V}$. The reduction peak in the $\mathrm{CV}$ graph indicates the discharging process of the LIB since delithiation occurs in anode materials.

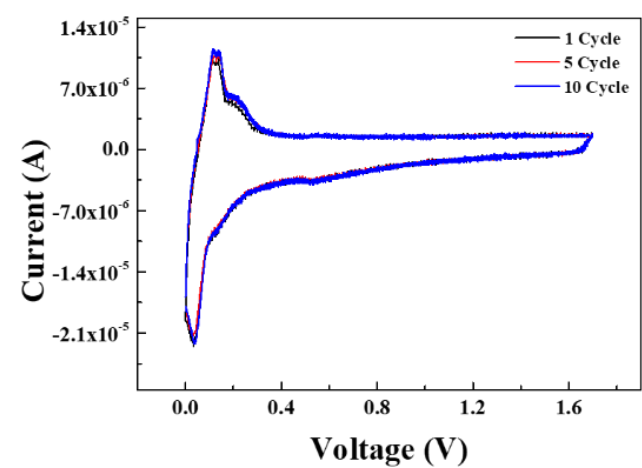

(a)

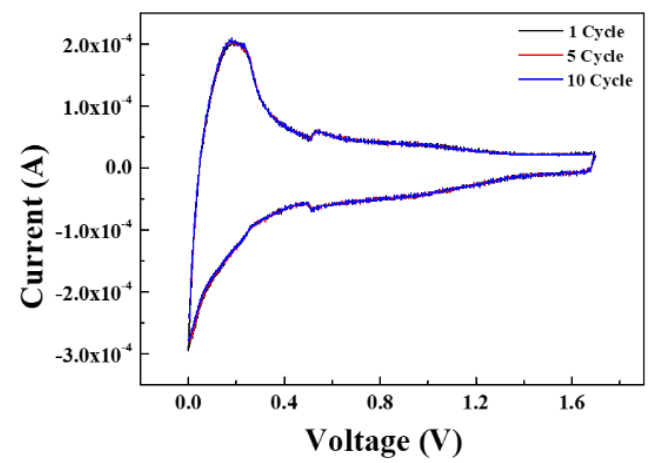

(c)

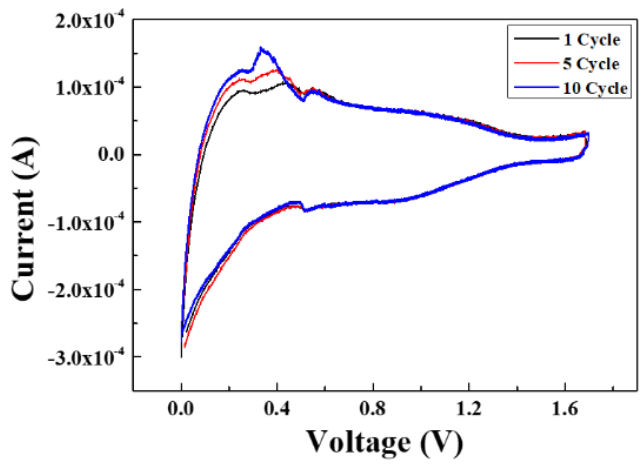

(b)

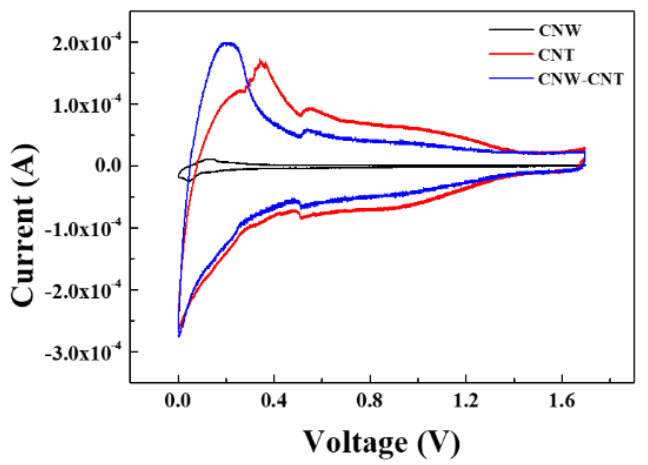

(d)

Figure 5. The CV graphs of (a) CNW, (b) CNT and (c) composite material for 1, 5, 10 cycle. (d) The $\mathrm{CV}$ graph of the 12th cycle for each of the samples.

Figure 5 a shows the two reduction peaks at $0.03 \mathrm{~V}$ and $0.53 \mathrm{~V}$. Figure $5 \mathrm{~b}$ shows one reduction peak at $0.51 \mathrm{~V}$, while Figure $5 \mathrm{c}$ shows the one reduction peak at $0.51 \mathrm{~V}$. Although there is a slight increase, Figure 5a shows the increment of the oxidation peak according to the cycle number in the CV graph of CNW. In Figure 5b, the CV graph of the CNT also shows the increment of the oxidation peaks according to cycle number. However, in Figure $5 c$, the CV graph of composite material with CNW and CNT does not show the increment of the oxidation peaks. In the CV graph, the increment of the oxidation peak indicates the increment of the specific capacity and good stability in the charging process. In the paper reported by Lin et.al, a CV graph with a similar trend was presented for graphene nanowalls [14].

The specific capacity of the LIB can be calculated in the CV graph by the internal area, mass of the anode materials, and scan rate. The internal area of the CV graph can be confirmed using the Origin program. $C_{p}[\mathrm{mAh} / \mathrm{g}]$ is the specific capacity of the LIB, $A$ [VA] is the internal area of the CV graph, $m$ is the mass of the anode materials, and $k[\mathrm{mV} / \mathrm{s}]$ is 
the scan rate of the CV graph. The equation for calculating the specific capacity of the LIB is shown below [15].

$$
C_{p}=\frac{1}{2 \mathrm{~km}} \int i(v) d v[\mathrm{As} / \mathrm{mg}]=\frac{1000 \mathrm{~A}}{7.2 \mathrm{mk}}[\mathrm{mAh} / \mathrm{g}]
$$

The specific capacities for each sample, calculated using Equation (1), are shown in Figure 6. In the CV graphs of the CNW and CNT, the increment of the peaks are shown according to the cycle number. This way, the tendency of each specific capacity is to increase according to the cycle number. In contrast, the composite material, with CNW and CNT of a specific capacity, shows a declining tendency by the slope -0.097 . The average specific capacity in 12 cycles is $62.4 \mathrm{mAh} / \mathrm{g}$ for CNW, $49.54 \mathrm{mAh} / \mathrm{g}$ for CNT, and $64.94 \mathrm{mAh} / \mathrm{g}$ for the composite material. The internal area of $\mathrm{CNW}$ is very small compared to that of CNT in Figure 5d, this is because the mass of the CNW is also very small. Small mass is at an advantage, and it indicates that more lithium-ions can be stored in the small mass of CNW. The specific capacity of the composite material was calculated to be higher than that of CNW and CNT. As such, using CNW and CNT as a composite material has the advantage of high specific capacity. The composite material can store more lithium-ions by compensating CNT for large defects in the wall structure of CNW, resulting in the increment of specific capacity.

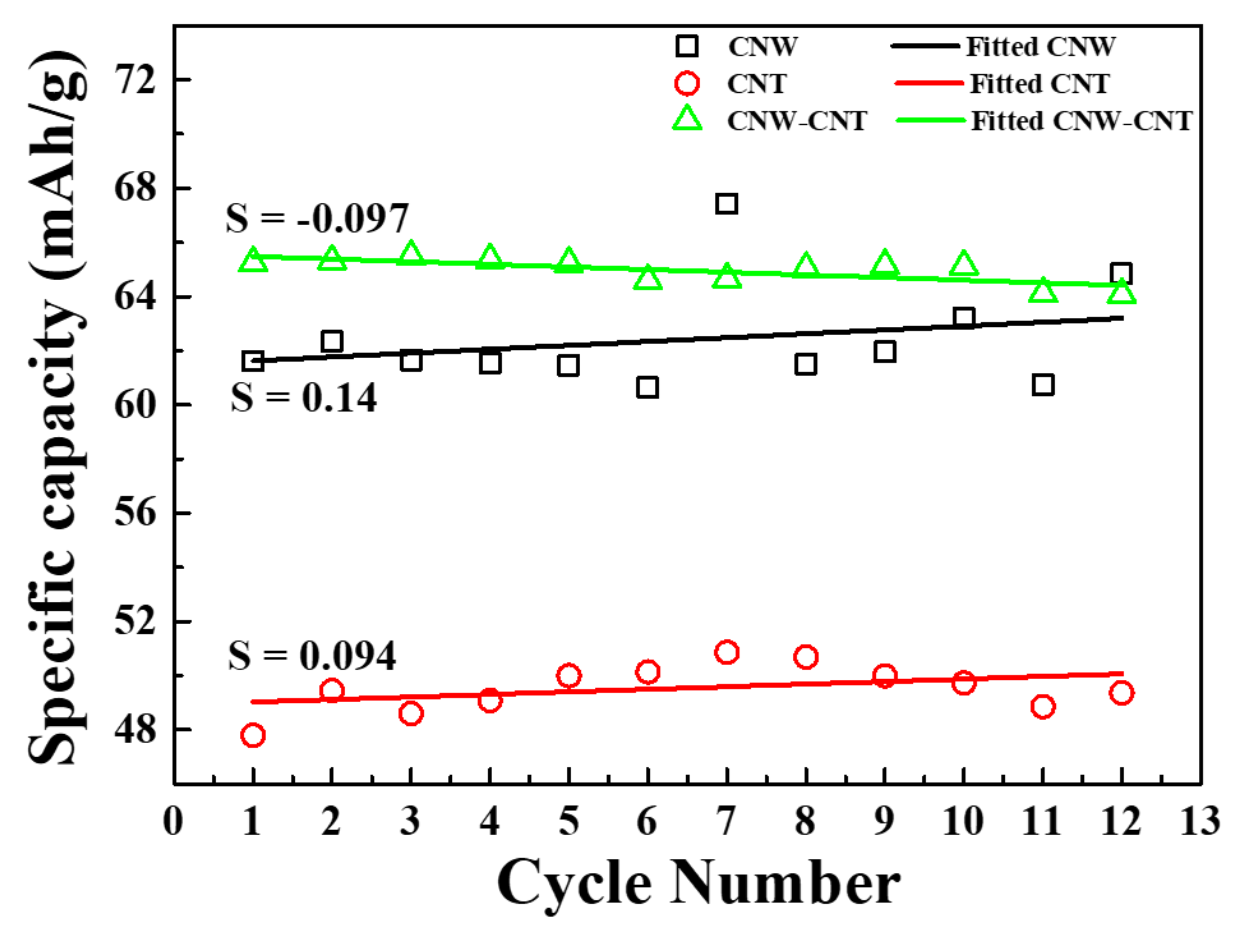

Figure 6. The Specific capacity of the CNW, CNT, and composite material for 12 cycles.

\section{Conclusions}

In this work, the CNW, CNT, and composite material are prepared as anode materials to investigate the properties of LIB. FE-SEM image and Raman analysis were employed to examine the structure of each sample. In Raman shift, we found that the CNT synthesized on CNW can reduce defects that occur in the wall structure of CNW. Coin cells were manufactured by each sample to investigate the electrochemical properties. CV analysis was performed on the coin cells to calculate the specific capacity of each cell. Once the specific capacity calculated using the $\mathrm{CV}$ graph for each cycle, we noticed that the composite material with CNW and CNT is represents the best specific capacity. In the composite material, the CNT can compensate for the defect of CNW that has the advantage of storing 
many lithium-ions in a small mass. For this reason, the composite material's specific capacity was shown to be optimal.

Author Contributions: Conceptualization, S.L. and W.C.; Data curation, S.L., S.K., K.K., H.K. and J.M.K.; Formal analysis, S.L.; Investigation, S.L. and S.K.; Supervision, W.C.; Writing—original draft, S.L. All authors have read and agreed to the published version of the manuscript.

Funding: This work was supported by the Korea Institute of Energy Technology Evaluation and Planning (KETEP), the Ministry of Trade, Industry and Energy (MOTIE) of the Republic of Korea (No. 20204030200080) and the Korea Electric Power Corporation. (Grant number: R17XA05-01).

Institutional Review Board Statement: Not applicable.

Informed Consent Statement: Not applicable.

Data Availability Statement: The data presented in this study are available from the corresponding author on reasonable request.

Conflicts of Interest: The authors declare no conflict of interest.

Sample Availability: Samples of the carbon nanowall and carbon nanotube are available from the authors.

\section{References}

1. Yang, Y.; Ni, C.; Gao, M.; Wang, J.; Liu, Y.; Pan, H. Dispersion-strengthened microparticle silicon composite with high antipulverization capability for Li-ion batteries. Energy Storage Mater. 2018, 14, 279-288. [CrossRef]

2. Xie, L.; Tang, C.; Bi, Z.; Song, M.; Fan, Y.; Yan, C.; Li, X.; Su, F.; Zhang, Q.; Chen, C. Hard Carbon Anodes for Next-Generation Li-Ion Batteries: Review and Perspective. Adv. Energy Mater. 2021, 11, 2101650. [CrossRef]

3. Zhao, W.; Wen, J.; Zhao, Y.; Wang, Z.; Shi, Y.; Zhao, Y. Hierarchically Porous Carbon Derived from Biomass Reed Flowers as Highly Stable Li-Ion Battery Anode. Nanomaterials 2020, 10, 346. [CrossRef] [PubMed]

4. Nam, K.H.; Chae, K.H.; Choi, J.H.; Jeon, K.J.; Park, C.M. Superior carbon black: High-performance anode and conducting additive for rechargeable Li- and Na-ion batteries. Chem. Eng. J. 2021, 417, 129242. [CrossRef]

5. Roald, H.; Artyom, A.K.; Andrey, A.G.; Davide, M.P. Homo Citans and Carbon Allotropes: For an Ethics of Citation. Angew. Chem. 2016, 55, 10962-10976.

6. Kharisov, B.I.; Kharissova, O.V. Classic Carbon Nanostructures. In Carbon Allotropes: Metal-Complex Chemistry, Properties and Applications; Springer Nature Switzerland AG: Gewerbestrasse, Switzerland, 2019; pp. 35-110.

7. Elena, F.S.; Yevgeny, A.G.; Nadezhda, A.P. Graphene Domain Signature of Raman Spectra of sp ${ }^{2}$ Amorphous Carbons. Nanomaterials 2020, 10, 2021.

8. Lei, L.; Hailin, P.; Zhongfan, L. Chemistry Makes Graphene beyond Graphene. J. Am. Chem. Sosiety 2014, 136, 12194-12200.

9. Plano, L.S.G. Growth of CVD Diamond for Electronic Applications. In Diamond: Electronic Properties and Applications, 1st ed.; Pan, L.S., Kania, D.R., Eds.; Springer: New York, NY, USA, 1995; pp. 61-138.

10. Mildred, S.D.; Ado, J.; Mario, H.; Gene, D.; Riichiro, S. Perspectives on Carbon Nanotubes and Graphene Raman Spectroscopy. Nano Lett. 2010, 10, 751-758.

11. Casiraghi, C.; Hartschuh, A.; Qian, H.; Piscanec, S.; Georgi, C.; Fasoli, A.; Novoselov, K.S.; Basko, D.M.; Ferrari, A.C. Raman Spectroscopy of Graphene Edges. Nano Lett. 2009, 9, 1433-1441. [CrossRef]

12. Yang, Q.; Wu, J.; Li, S.; Zhang, L.; Fu, J.; Huang, F.; Cheng, Q. Vertically oriented graphene nanowalls: Growth and application in Li-ion batteries. Diam. Relat. Mater. 2019, 91, 54-63. [CrossRef]

13. Ferrari, A.C.; Meyer, J.C.; Vittorio, S.; Casiraghi, C. Raman Spectrum of Graphene and Graphene Layers. Phisical Rev. Lett. 2006, 97, 187401. [CrossRef] [PubMed]

14. Lin, G.; Wang, H.; Zhang, L.; Cheng, Q.; Gong, Z.; Ostrikov, K. Graphene nanowalls conformally coated with amorphous/nanocrystalline Si as high-performance binder-free nanocomposite anode for lithium-ion batteries. J. Power Sources 2019, 437, 226909. [CrossRef]

15. Conway, B.E. Energetics and Elements of the Kinetics of Electrode Processes. In Electrochemical Supercapacitors: Scientific Fundamentals and Technological Applications; Springer Science + Business Media: New York, NY, USA, 1999 ; pp. 33-66. 